\title{
ESTÁGIO CURRICULAR SUPERVISIONADO: CONCEPÇÕES DOS ACADÊMICOS DO CURSO DE LICENCIATURA EM EDUCAÇÃOO DO CAMPO - ARTES VISUAIS E MÚSICA DA UNIVERSIDADE FEDERAL DO TOCANTINS, CÂMPUS ARRAIAS
}

\author{
Solange Martins Oliveira Magalhães (D1, Sílvia Adriane Tavares de Moura (D)2
}

Resumo: O artigo apresenta os resultados de uma pesquisa que busca compreender as perspectivas de estudantes matriculados nos Estágios Curriculares Supervisionados I e II, do Curso de Licenciatura em Educação do Campo: Artes Visuais e Música na UFT, Campus de Arraias, sobre as experiências no estágio, considerado como expressão da indissociabilidade da relação teoria e prática, a partir de uma concepção de Educação do Campo crítica e contra hegemônica. Pautando-nos na matriz teórica do Materialismo Histórico-dialético, discutimos a trajetória do estágio, suas aproximações ou lacunas entre formação e atuação como componente da historicidade do curso analisado. Os resultados mostram que o estágio possibilita aos/às estudantes, subsídios e elementos teórico-práticos relacionados à prática curricular, evidenciando a complexidade do trabalho docente no estágio, mas ainda se encontra distanciado do entendimento mediante o que vem a ser a indissociabilidade entre teoria e prática, o que permite a manutenção de uma concepção dicotômica de estágio. Os resultados da pesquisa nos permitem recomendar que o Estágio Curricular Supervisionado (ES) promove a conscientização do que seja uma educação crítica numa perspectiva de qualidade social, mas ainda se faz necessário avançar na construção de um discurso e ideário pedagógico literalmente articulado à concepção de educação libertadora. O Estágio também evidenciou a necessidade de intensificar a ênfase aos aspectos constitutivos de uma concepção de Educação do Campo, a partir de uma lógica revolucionária, contra hegemônica, em respeito à luta e militâncias dos movimentos sociais.

Palavras-chave: Educação do Campo; Estágio Curricular Supervisionado; Formação Docente; Trabalho Educativo.

\section{SUPERVISED CURRICULAR INTERNSHIP: CONCEPTIONS OF THE ACADEMICS OF THE UNDERGRADUATE COURSE IN RURAL EDUCATION - VISUAL ARTS AND MUSIC AT THE FEDERAL UNIVERSITY OF TOCANTINS CAMPUS ARRAIAS}

Abstract: The article presents the results of a research that seeks to understand the perspectives of students, enrolled in Supervised Curricular Internships I and

\footnotetext{
${ }^{1}$ Doutora em Educação pela Universidade Federal de Goiás (UFG). Professora Titular da Universidade Federal de Goiás (UFG) e do Programa de Pós-Graduação em Educação (PPGE-FEUFG). E-mail: solufg@hotmail.com.

${ }^{2}$ Doutoranda do Programa de Pós-graduação em Educação, da Universidade Federal de Goiás (UFG). Professora no Curso de Licenciatura em Educação do Campo: Artes Visuais e Música na Universidade Federal de Tocantins (UFT). E-mail: silviaadriane@uft.edu.br.
} 
II, of the Degree Course in Rural Education: Visual Arts and Music at UFT, Campus de Arraias, about the experiences in the internship considered as an expression of the inseparability of the relationship between theory and practice from a critical and counter hegemonic conception of Field Education. Based on the theoretical matrix of Dialectical Historical Materialism, we discuss the trajectory of the internship, its approximations or gaps between training and performance as a component of the historicity of the analyzed course. The results show that the internship allows students, subsidies and theoretical and practical elements related to the curricular practice that shows the complexity of the teaching work in the internship, but is still distanced from the understanding through what is the inseparability between theory and practice, which allows the maintenance of a dichotomous concept of internship. The results of the research allow us to recommend that the Supervised Curricular Internship (ES) promotes the awareness of what is a critical education in a perspective of social quality, but it is still necessary to advance in the construction of a discourse and pedagogical ideas literally articulated to the concept of education liberating. The Internship also highlighted the need to emphasize the constitutive aspects of a concept of Rural Education, based on a revolutionary logic, against hegemony, with respect to the struggle and militancy of social movements.

Keywords: Rural Education; Supervised internship; Teacher Education; Educational Work.

\section{Introdução}

O diálogo aqui construído, apresenta reflexões em torno do tema formação de professores/as da Educação Básica, com foco no Curso de Licenciatura em Educação do Campo/Artes Visuais e Música, Universidade Federal do Tocantins, Campus Universitário de Arraias. Desenvolvemos uma pesquisa fundamentada no arcabouço teórico Materialista Histórico Dialético, que teve como objetivo principal identificar as experiências de estudantes matriculados no Estágio Curricular Supervisionado I e II, durante o período 2017-2018 do curso supracitado, buscando compreender o processo de materialização do Estágio da primeira turma de acadêmicos, bem como as concepções dos acadêmicos acerca de suas experiências formativas diante dos principais desafios encontrados pelos estudantes e docentes do Curso na realização do estágio supervisionado no curso de Licenciatura em Educação do Campo, com formação na área especifica de Códigos e Linguagens- Artes Visuais e Música, ofertado pela Universidade Federal do Tocantins, Câmpus Universitário de Arraias.

Buscamos compreender ainda as perspectivas teóricas e epistemológicas destacadas no âmbito do Estágio Curricular Supervisionado em um curso inovador, tomando como referência fundamental, uma concepção de Educação do Campo crítica e o como esta poderia estar articulada à formação teórica e/ou as temáticas abordadas no espaço da universidade, nos espaços concedentes para a realização do estágio, ou seja, no campo social do estágio e ainda, se 
explicitariam a indissociabilidade entre teoria e prática tendo em vista que o estágio apresenta potencial para contribuir com a melhoria do ensino de Artes Visuais e da Música e o fortalecimento das conquistas da Educação do Campo.

\section{Metodologia}

Metodologicamente, pautando-nos na matriz teórica do Materialismo Histórico-dialético, por meio de uma abordagem qualitativa, subsidiada pelas Pesquisas Bibliográfica e Documental, fundamentas por Lima e Mioto (2007). As informações foram coletadas por meio da análise documental, contendo sistematizações dos estudantes expressas em relatórios de estágio como componente curricular obrigatório e síntese das experiências em sala de aula. Ainda foram realizados vários debates acerca da contribuição da formação "espaço-tempo formativo voltado à práxis" (SILVA, 2020, p. 11), esclarecendo sobre o como poderiam subsidiar as práticas do estágio com as vivencias nas Comunidades Integradoras. ${ }^{3}$

A pesquisa assume o desafio de debater a temática do Estágio Curricular Supervisionado, optando por enfatizar a concepção de estágio assumida, suas proposições legais, compondo a historicidade curso. Como recorte empírico, apresentamos a análise das informações sobre a concepção de Educação do Campo identificada, e se as práticas mencionadas poderiam ser relacionadas às elucidações, por parte dos estudantes, da relação teoria e prática, como pretendido pelo curso de formação de professores específica dos povos do campo.

Entendemos o estágio como uma disciplina obrigatória na formação dos profissionais em formação e no campo educacional, em específico, se configura como um componente curricular que aproxima teoria e prática, sendo que o conhecimento teórico por si só não se transforma em conhecimento prático e que a prática não substitui a teoria, e ainda, situam os acadêmicos no contexto em que irão atuar, cujas experiências se relacionam com os estudos acadêmicos, aspectos que revelam a sua importância para a formação dos acadêmicos em direção ao ingresso no campo profissional.

\section{Resultados e discussões}

3.1. Educação do campo: concepção, proposições legais, historicidade do curso da Universidade Federal do Tocantins (UFT)

Historicamente, a Educação do Campo, como princípio e conceito, nasceu assentada na luta pelo direito que os sujeitos do campo possuem à uma educação diferenciada daquela oferecida a quem vive nas cidades. As reflexões

\footnotetext{
${ }^{3}$ Definimos o termo Comunidade Integradora como forma específica de identificar a diversidade de regiões atendidas pelo Curso e que agregam estudantes de vários municípios em uma mesma comunidade ao propor atividades pedagógicas e metodológicas no Tempo Comunidade, diferenciando-se de dinâmicas vivenciadas durante o Tempo Universidade. Encontram-se nomeadas, até o presente momento as seguintes comunidades: Arraias, Paranã, Monte Alegre e Taguatinga, podendo haver alterações mediante o prfil identitário dos estudantes que adentram anualmente no Curso.
} 
acerca da Educação do Campo não podem ocorrer de forma descolada do contexto social, político e econômico de luta pela terra (BEZERRA; LIMA, 2013). Nesse sentido, a Educação do Campo, como uma proposta de educação que busca romper com as cercas do latifúndio que limitam o acesso ao conhecimento universal e a valorização e trocas dos diversos saberes específicos dos povos do campo, se constitui como práxis pedagógica de resistência e contra hegemonia. O Movimento Nacional por uma Educação do Campo é seu mais forte defensor e a partir de seus intelectuais orgânicos, militam por uma Legislação pertinente à Educação do Campo e por marcos normativos pensados a partir do campo e para o campo, que contemplem as especificidades, singularidades e particularidades das populações identificadas com o campo, sem perder de vista a relevância do seu acesso ao conhecimento universal sistematizado pela humanidade.

A militância organizada pelo Movimento por uma Educação do Campo, preconiza a superação do antagonismo entre cidade e o campo, que passam a serem vistos como complementares e de igual valor. Simultaneamente, considera-se e respeita-se a existência de tempos e modos diferentes de ser, viver e produzir, contrariando a pretensa superioridade do urbano sobre o rural e admitindo variados modelos de organização da educação e da escola. Concepção que é assumida pelo curso de Licenciatura em Educação do Campo/Artes Visuais e Música, da Universidade Federal do Tocantins, Campus Universitário de Arraias, e isso já é considerado como uma avanço, sobretudo no que se refere a formação de educadores pensada pelo e para o campo.

Em seu currículo defende-se uma concepção de Educação do/no Campo, como um instrumento de luta da classe trabalhadora rural, como processo de construção do homem do campo. Caldart (2012), sustenta uma Educação do Campo que perpassa os objetivos do curso. Essa concepção é vista como

\begin{abstract}
uma prática social que não se compreende em si mesma e nem apenas a partir das questões da educação, expondo e confrontando as contradições sociais que a produzem. E são estas mesmas características que também podem configurá-la como categoria de análise das práticas por ela inspiradas ou de outras práticas que não atendem por esse nome nem dialogam com essa experiência concreta. A tríade campo-educaçãopolítica pública pode orientar perguntas importantes sobre a realidade educacional da população trabalhadora do campo onde quer que ela esteja. (CALDART, 2012, p. 264-265).
\end{abstract}

A concepção defendida pela autora é por nós assumida, sobretudo por indicar que seria pela educação que os sujeitos se apropriam do conhecimento produzido por outras gerações, bem como valores, formas de se organizar, de pensar e de agir no mundo. Premissas que se ligam aos aspectos da formação e nos reportam aos estágios supervisionados, como espaço de reflexão contextualizada.

Conforme proposta do curso da UFT, a Educação do Campo exige uma formação que passa por grandes áreas, com habilitação articulada em duas linguagens das Artes - Artes Visuais e Música - o que a configura uma proposta contemporânea e inovadora, como lócus das práticas interdisciplinares. A matriz curricular do curso segue essa lógica interdisciplinar sendo organizada em quatro 
áreas do conhecimento: Linguagens (expressão oral e escrita em Língua Portuguesa, Artes, Literatura); Ciências Humanas e Sociais; Ciências da Natureza e Matemática e Ciências Agrárias. Como sustentaram Molina e Sá $(2013$,$) trata-se de uma organização que implica em novos espaços curriculares$ que articulam componentes tradicionalmente disciplinares, fazendo-os dialogar entre si a partir de recortes complementares e interdisciplinares. O diálogo visa superar a fragmentação tradicional proposta por uma formação disciplinar, embora articular suas áreas de formação específicas - Artes Visuais e Música, ainda seja um grande desafio.

O desafio da formação por áreas do conhecimento, evoca pensarmos sobre o trânsito entre as áreas envolvidas no conjunto das disciplinas previstas, que passam pela formação geral por intermédio dos fundamentos didáticometodológicos, sem perdermos de vista o foco em cada componente curricular, pois todos são articulados a identidade profissional e a atuação docente. Além disso, ainda exige pensarmos sobre formas não hierárquicas de lidar com os conteúdos, bem como suas significações em/sobre os modos de produção dos sujeitos do conhecimento, potencializando interdisciplinarmente as experiências e devires, com vistas à transformação das relações do/no trabalho educativo, o que deve expressar-se no campo de estágio.

Ainda destacamos outras legislações que fundamentaram o curso da UFT: Constituição Federal de 1988 e a Lei de no 9394/96 (LDB), que fixam Diretrizes e Bases da Educação Nacional, Lei no $11.788 / 2008$ e sua notificação recomendatória; A Resolução nº1 e 02 /2002-CNE/CP, que instituem as Diretrizes Curriculares Nacionais para a Formação de Professores da Educação Básica que consideram as especificidades da Educação do Campo. Tal como versam a Resolução CNE/CEB $n^{0} 1$, de 03/04/2002, que estabelecendo as Diretrizes Operacionais para a Educação Básica nas Escolas do Campo; o Decreto no 7.352, de 04 de novembro de 2010, que dispõe sobre a política de Educação do Campo e o Programa Nacional de Educação na Reforma Agrária (PRONERA) e a Resolução no 03/2005 do Conselho de Ensino Pesquisa e Extensão (CONSEPE) e, por fim, o Manual e Notas Técnicas para Estágios Obrigatórios e Não Obrigatórios da Pró-Reitoria de Graduação (PROGRAD) (BARRA, 2020; MAGALHÃES; MOURA, 2020).

Na particularidade da Lei de No 11.769 de 18 de agosto de 2008, que altera a Lei no 9.394, de 20 de dezembro de 1996, Lei de Diretrizes e Bases da Educação, temos a obrigatoriedade do ensino da música na educação básica, afirmando no parágrafo $6^{\circ}$ que a música deverá ser conteúdo obrigatório, mas não exclusivo, do componente curricular. Na mesma direção, a Lei de No 13.278 de 02 de maio de 2016, altera o $\S 6^{\circ}$ do art. 26 da Lei $n^{\circ} 9.394$, de 20 de dezembro de 1996 e que fixa as diretrizes e bases da educação nacional referente ao ensino da Arte, ficando registrada da seguinte forma: [...] As artes visuais, a dança, a música e o teatro são as linguagens que constituirão o componente curricular de que trata o $\S 2^{\circ}$ deste artigo.

No entanto, como argumenta Gomes (2020, p. 12), apesar da legislação, existem deficiências relativas, por exemplo, à educação musical como componente curricular de Arte - aspecto que diz respeito ao curso estudado. 0 autor destaca que no que diz respeito à Arte, a legislação mantém latente um 
conflito entre duas concepções distintas de educação artística: aquela defendida na LDB de 1971 (Lei n. ${ }^{\circ}$ 5.692, de 11 de agosto de 1971) e, a outra, a que pode ser aferida da atual versão do $\S 60^{\circ}$ do artigo $26 .^{\circ}$ da LDBEN de 1996 (Lei n. 0 9.394, de 20 de dezembro de 1996).

Para Gomes (2020), isso ocorre porque na LDB de 1971 a concepção de educação artística é entendida como sendo caracterizada por uma perspectiva integradora das diversas linguagens artísticas, o que possibilitou a que na prática a referida Educação Artística tornasse-se quase que um sinônimo de artes visuais, acabando por retirar espaço às restantes linguagens artísticas. Já na redação da atual LDBEN (1996), passou a conceber um espaço curricular distinto que deverá ser ocupado, dentro da componente curricular de Arte, por cada uma de quatro linguagens artísticas expressamente aí mencionadas: artes visuais, dança, música e teatro (GOMES, 2020). De fato, como advoga Gomes (2020, p.12), passou-se de uma "concepção integradora das diversas linguagens artísticas para uma visão curricular que as distingue", assumindo-se uma perspectiva disciplinar autônoma destas, por isso ele sustenta que houve um retrocesso conceitual, uma vez que são desconsideradas as especificidades inerentes a cada uma das referidas linguagens.

Esses aspectos somam-se a outros dilemas relacionados às especificidades da matriz curricular do curso - Artes Visuais e Música em Arraias, dilemas relacionados a realidade das escolas do campo no Estado do Tocantins, reportados pelos estudantes, conforme mostrou a presente pesquisa. Gomes (2020, p. 12), destacou em tom de denúncia que é constatar que no Estado do Tocantins, como em tantos outros estados da União (SOUZA; FARIA; SARAT, 2019), deparam-se com muitas determinações postas nas legislações, ainda carecem de efetivo cumprimento no espaço da escola, como por exemplo, a disciplina de Educação Musical enfrenta retrocessos, pois,

\footnotetext{
foi a retirada da disciplina de Educação Musical das novas grades curriculares da rede estadual de ensino que vigoram desde 2017 - diluindoa nas disciplinas de Arte e de Produção e Expressão Artística -, ou mesmo uma sensível mudança das políticas nesta área por parte da Prefeitura Municipal de Palmas, Tocantins, ao não prever a contratação de professores devidamente habilitados nesta área no processo de contratação levado a cabo para o ano escolar de 2019 (GOMES, 2020, p. 12)
}

Trouxemos a contribuição de Gomes (2020) para exemplificar que a matriz curricular do curso da UFT enfrenta as mesmas dificuldades, embora a Lei de Diretrizes e Bases da Educação Nacional LDB no 9394/96, ampare e exija que a formação docente inclua uma prática de ensino voltada as artes e música, sustentando, inclusive, legalmente os estágios supervisionados como atividades de prática pré-profissional voltadas a formação solicitada pela LDB, esse aspecto ainda não é respeitado. Os estagiários vivem isso.

A despeito das dificuldades, o curso de Licenciatura em Educação do Campo/Artes Visuais e Música, da UFT, responde às exigências dos movimentos sociais em relação aos povos do campo, mas convém observar que isso exige enfrentamento de políticas públicas que visam destituir o (re)conhecimento do lugar das linguagens artísticas na/para a formação intelectual dos indivíduos, o 
que não poderia deixar de ser e existir na universidade pública e em seus cursos de formação de professores.

3.2. O Curso de Licenciatura em Educação do Campo/UFT/ Campus Universitário de Arraias: descrição do estágio curricular

Caldart (2012) nos apoia na configuração de uma concepção de Educação do Campo, mas também reforça a concepção de estágio adotada no curso, ambas possibilitam aos estudantes refletir sobre a educação e qual será sua função no cenário da educação do campo atual (ANJOS; BORGHI; PORTO, 2017). O PPC (2013) do curso continua sustentando uma perspectiva interdisciplinar ao destacar a ideia da necessidade de práticas efetivas e diferenciadas no momento do estágio curricular, exigindo que essas devem ser geradoras de novas experiências formativas que se ocupem da articulação entre teoria e prática, resultando na práxis docente.

Teoricamente, o PPC (2013) do curso assume uma concepção de estágio como atividade de pesquisa, e por isso se constitui como um campo de conhecimento. Portanto, por ser campo de conhecimento, sustenta um estatuto epistemológico que busca superar a normativa tradicional que reduz a prática docente à atividade prática instrumental, para ascender à práxis. Espera-se com essa concepção de estágio ajude a superar a dicotomia que existe entre teoria e prática, entendendo que ela se torna arraigada entre os estagiários em muitos cursos de formação.

Essa perspectiva de estágio ainda integra a formação docente com o campo social, entendendo que o estágio é capaz de desenvolver mediações transformadoras por meio do trabalho educativo (PIMENTA; LIMA, 2006; SILVA, 2020). Proposição que é sustentada pela lógica dialética que também ajuda a desvelar os interesses voltadas à Educação do Campo, postos nas políticas educacionais, suas implicações frente as diversidades dos povos dos sertões e das florestas, caiçaras, ribeirinhos, assentados, agricultores familiares. A abordagem materialista histórica e dialética visa superar as atuais relações de dominação (SILVA; PASUCH, 2010). Nesse sentido, o Estágio como componente curricular influi na construção da identidade docente para que ela seja politizada, capaz de mobilizar o trabalho educativo no sentido de intervenção na prática social (ANJOS; BORGHI; PORTO, 2017).

No Projeto Pedagógico Curricular do curso (PPC, 2013), o Estágio Supervisionado exige a articulação dos professores das diferentes áreas, além do apoio dos movimentos acadêmicos, por meio de diversos tipos de reuniões, estudos e propostas que têm sido pensadas, em âmbito institucional, tanto no interior da universidade, quanto nas instituições parceiras e escolas estagiais, para que a experiência do estágio seja momento importante no processo formativo. Ele deve ampliar e diversificar as oportunidades de parcerias educativas e, conforme mostram Anjos, Borghi e Porto (2017, p. 2), precisa ser "ferramenta de aproximação, onde os licenciandos desenvolvem as práticas educativas, aliando o conhecimento teórico ao prático".

Isso implica numa organicidade em torno dos encaminhamentos e tomadas de decisões sobre o Estágio em âmbito da Licenciatura em Educação 
do Campo: Artes Visuais e Música em Arraias. Trabalham de forma articulada à Legislação Nacional Vigente, aos Marcos Normativos Institucionais da UFT, bem como a Proposta Pedagógica Curricular do Curso, que está sob orientação da Pró-reitoria de Graduação, Central de Estágio, da Coordenação do Curso, do Núcleo Docente Estruturante e do Colegiado, que deliberou pela efetivação da Coordenação de Estágio, interlocução que resultou no Regulamento do estágio, o qual dispõe sobre Diretrizes que orientam a organização e normatização das atividades curriculares, dinâmicas e encaminhamentos do Estágio Supervisionado (BARRA, 2020). Coletivamente, o processo garante a unidade de princípios e ações no processo de desenvolvimento do Estágio Supervisionado, e esses princípios seguem o Regulamento do Estágio, que está em consonância com as especificidades e formas de organização pedagógicas contempladas na Proposta Pedagógica Curricular do Curso, especialmente no que se refere ao arcabouço teórico-conceitual e empírico, e as áreas específicas de conhecimento - Artes Visuais e Música.

Conforme suas diretrizes, o estágio segue integrando o itinerário formativo do estagiário, conforme Projeto Pedagógico do Curso (BRASIL, 2008, p.9). sendo assim definido na legislação:

\begin{abstract}
Art. 1을 Estágio é ato educativo escolar supervisionado, desenvolvido no ambiente de trabalho, que visa à preparação para o trabalho produtivo de educandos que estejam frequentando o ensino regular em instituições de educação superior, de educação profissional, de ensino médio, da educação especial e dos anos finais do ensino fundamental, na modalidade profissional da educação de jovens e adultos (BRASIL, 2008, p.04).
\end{abstract}

O Estágio Supervisionado está em concordância com as Diretrizes Curriculares Nacionais (DCN) para as licenciaturas no Brasil. Por exemplo, na Resolução $n^{\circ} 2$, de $1^{\circ}$ de julho de 2015 , em seu capítulo $V$, as temos que a "Formação Inicial do Magistério e para a Formação Continuada", há a exigência de estágio supervisionado de 400 horas na área de formação e atuação na educação básica, para cursos com no mínimo 3.200 horas de trabalho efetivo. Para a Educação do Campo da UFT, em seu PPC (2013) encontra-se prevista uma carga horária de 405 horas.

Vislumbra-se que o estágio no Curso de Educação do Campo/UFT possibilite ao acadêmico a experiência do "ato educativo escolar supervisionado, desenvolvido no ambiente de trabalho, que visa à preparação para o trabalho produtivo do estudante, como delibera a Lei no 11.788 , de 25 de setembro de 2008.

Conforme prescrito em regulamento, o Curso de Licenciatura em Educação do Campo da UFT, Arraias, organiza o estágio em etapas formativas, a saber: a) Disciplina de Estágio Curricular Supervisionado I, na qual os acadêmicos (as) realizam observação; b) Disciplina de Semirregência II, em que os (as) discentes são orientados (as) pelos (as) docentes das Áreas Pedagógicas e Humanidades; c) Disciplina de Regência-Estágio Supervisionado III, na qual, os(as) licenciandos(as) são orientados(as) pelos (as) professores(as) especialistas nas áreas de Artes Visuais e Música, nessa etapa os sujeitos são subdivididos de 
acordo com a Comunidade Integradora em articulação com o trabalho realizado mediante às outras Disciplinas de modo interdisciplinar. Em seguida, há a etapa de sistematização, apresentação e exposição dos relatórios, tanto em sala de aula quanto em outras ações planejadas pelos sujeitos, tal como Seminários de Estágio. Este, por sua vez, pode ser utilizado para compreender processos e aspectos da escola, esclarecer as formas de organização e as etapas do estágio, bem como ter direcionamento da instituição (escola e do curso), quanto aos conteúdos e processos interativos/ interventivos de aprendizagem, para poder exercer a docência. Essas etapas sinalizam que o estágio é um ponto crucial, almejado, desafiador e por vezes nevrálgicas no curso referido curso.

No que se referem às cargas horárias destinadas ao Estágio Supervisionado (ES) I e II são respectivamente, 60 horas teóricas para o ES I e 90 horas práticas para o ES II. Sua distribuição é pensada de modo a contemplar atividades no Tempo Universidade (T.U) e Tempo Comunidade (T.C), bem como, a realidade dos campos de estágios. A Regência é estruturada em etapas seguintes sendo exercida nas Disciplinas Estágio Supervisionado III e IV, orientados/as e acompanhados/as pelos/as professores/as das áreas especificas: Artes Visuais e Música. E ainda, conforme constam nas propostas das Disciplinas, o estágio tem por finalidade propiciar condições para que o/a acadêmico/a possa conhecer a dinâmica prevista para a iniciação à docência, sobretudo o conhecimento do contexto da escola/campo a partir da observação das experiências pedagógicas docentes que o conduza à análise e reflexão sobre o processo ensino aprendizagem das Artes Visuais e da Música, mediados por atividades planejadas, desenvolvidas e avaliadas durante o processo.

Durante a realização dos estágios no Tempo Comunidade (T.C), ocorre a socialização parcial do processo em andamento e no retorno ao Tempo Universidade (T.U), já com a carga horária concluída, há a realização do I Seminário de Socialização das Experiências do Estágio. No espaço acadêmico, cada estagiário, em seu grupo de colegas pertencentes a cada Comunidade Integradora ou por campos de estágios singulares, expõe suas vivências, expectativas, desafios, superações, possibilidades e potencialidades frente ao estágio.

Ao final do Estágio Curricular Supervisionado I e II, os alunos participaram de intervenções didáticas, articulando metodologias, contextos e possibilidades estabelecer conexões entre o estágio, considerando-o também, como objeto de pesquisas e iluminando temáticas em Trabalhos de Conclusão de Curso (ANJOS; BORGHI; PORTO, 2017). Desse modo, a Coordenação de Estágio e o Professor Orientador procuram garantir as condições para que os acadêmicos desenvolvam suas atividades de modo que este trabalho auxilie na (re)estruturação do currículo escolar, considerando as condições e características das escolas-campo e da própria universidade, uma vez que estudantes campesinos vivenciam práticas e espaços de vivência - cultura e trabalho - diferenciados dos estudantes urbanos.

Concluímos que a concepção de estágio adotada pelo curso, segue a definição de Pimenta e Lima (2004), como "[...] eixo central na formação de professores, pois é através dele que profissional conhece os aspectos indispensáveis para a formação da construção da identidade dos saberes do dia 
a dia" (PIMENTA; LIMA, 2004, p. 12). Essa concepção, no nosso entendimento, ultrapassa sua condição de disciplina obrigatória, realçando suas potencialidades de interação comunitária e interventiva. Ele torna-se campo de conhecimento, capaz de intervir no social.

3.3. Licenciatura em Educação do Campo/UFT/Arraias: relatos das experiências dos/as estagiários (as) nas escolas campo

Abordar os modos de organização em torno do Estágio Curricular Supervisionado/UFT/Arraias requer compreender que se trata de uma área de formação do conhecimento que necessita estar interligada em uma dimensão teórica e prática, como apresentamos, e resultar, sempre que possível, em práxis educativa na Educação do Campo.

O estágio nos anos de 2017 e 2018 com entrega dos relatórios no primeiro semestre de 2019, contou com 70 estudantes matriculados/as nas Disciplinas de estágio, distribuídos na Comunidade Integradora, a saber: Arraias, Paranã, Monte Alegre e Taguatinga. Fizemos um recorte da leitura na integra dos relatórios de 32 estudantes que já haviam entregues em data prevista seus relatórios junto a Coordenação de Estágio. Dos 32 documentos lidos, fizemos a opção pelo recorte de 8 relatórios ( 8 acadêmicos (as), sendo 2 relatos (2 acadêmicos) de cada comunidade integradora (4 comunidades integradoras), compondo a visão da realidade regional.

Os dados foram coletados por intermédio da pesquisa documental, os quais, descreviam várias experiências, mas como já apontamos, nosso recorte foi direcionado nos aspectos relacionados a concepção de Educação do Campo, cujas práticas conseguissem traduzir a relação teoria e prática, como pretendido pelo curso de formação.

No que se refere a relação teoria e prática, o relato da estagiária Jasmim ${ }^{4}$, descreve o estágio como espaço de aprendizagem prática. A palavra prática nos remete a ideia de execução, realização, exercício, atividade, ação aplicada, desempenho que possibilita ao acadêmico, a construção da capacidade docente que efetivamente fundamentará a formação profissional do professor:

[...]. Com o estágio e vivenciando nesse período a realidade da sala de aula, vejo que /a professor/a, precisa ter a consciência de que o estágio é complexo, de que tipo de profissional precisa ser e proporcionar que outros sejam. Por isso os textos resenhados devem fazer parte da leitura de todo/a acadêmico/adentro das licenciaturas das diversas áreas na formação da docência (Estagiária Jasmim).

$O$ relato nos remete a complexidade que envolve as atividades vinculadas ao estágio, bem como as representações dos (as) estudantes, e embora o mesmo possa estar articulando teoria e prática, ainda é presente a ideia de que o estágio é o momento de pôr em prática o que se aprende de maneira teórica na universidade. Parece-nos que ainda está sendo reforçada entre os estudantes

\footnotetext{
${ }^{4}$ Atendendo aos princípios da pesquisa ética, utilizamos nomes fictícios para preservar a identidade dos (as)estudantes.
} 
uma ideia que não articula teoria e prática de forma indissociável no cotidiano da escola.

$O$ relato da estudante Margarida segue no mesmo sentido, descrevendo o estágio como realidade dicotômica entre o prescrito e o real, contemplando o que se encontra estabelecido pela legislação e o que de fato o estagiário encontra no campo, mas sem a manifestação consciente de que a capacidade de observar e ser crítica perante a realidade vivida, exige a articulação entre teoria e prática:

[...] quanto a parte pedagógica, vale destacar o empenho e a desenvoltura dos professores que ministram Arte na escola. Porém, a carga horária semanal e o tempo de cada aula se tornam entraves no trabalho docente. Além disso, a falta de espaço físico e o currículo precisam ser mais bem estruturados. Nesse currículo, vemos a ausência do ensino da música na escola e como discentes do curso de licenciatura em Artes Visuais e Música, sabemos que a falta da educação musical se torna uma lacuna na formação educativa dos alunos da Educação Básica (Estagiária Margarida).

No mesmo sentido, a estudante Papoula apresenta o como ela compreende os desafios e lacunas no que diz respeito ao contato com a prática no cotidiano escolar, sem fazer referência ao momento formativo que poderia suprir as deficiências do campo:

[...] A disciplina de música não é ministrada na escola, tendo seus conteúdos contemplados dentro das aulas de Arte. Porém, a professora da escola campo prefere não trabalhar nem um assunto relacionado a educação musical diretamente, uma vez que não se sente preparada totalmente para exercê-los. Nós poderíamos suprir essa dificuldade? (Estagiária Papoula).

A estudante Gardênia caminhou um pouco mais estruturando uma denúncia sobre a situação vivida pelos estagiários e sobre o posicionamento da escola:

[...] A unidade concedente está localizada na cidade e recebe também alunos oriundos do campo (...) a rotina desses alunos campesinos não segue a uma organização especifica pela escola, sendo assim, eles vivenciam uma série de problemas: o deslocamento dos estudantes de sua casa para a escola (transporte precário), má alimentação, cansaço físico, sono, déficit de atenção, desempenho escolar e consequentemente, perda de identidade étnica e cultural. Esses são problemas da escola também, deveriam ter soluções via escola (Estagiária Gardênia).

Gardênia relatou que havia certo esforço da escola na tentativa de se manter compromissada com a formação da criança do campo. Mas que entretanto, não retomou o apreendido durante sua formação, pois os problemas relacionados a Educação do Campo na atualidade são concretos e bastante discutidos pelas disciplinas do curso, o que poderia suscitar um debater sobre os aspectos teóricos de forma articulada ao vivido na experiência de estágio. Poderiam surgir posicionamentos mais críticos. 
Os relatos, em geral, mostram que o estágio favorece a abertura para o diálogo e troca de experiências no campo. Como descrito por Milanesi (2012) ele passa a fazer parte do desenvolvimento profissional, inclusive promovendo a articulação com dimensões pessoais, sociais, políticas, profissionais, organizacional, resultando aspectos valorativos relacionados ao tempo do estágio, das atividades desenvolvidas nas escolas, embora não tenha havido relatos sobre como apoiam aspectos da formação inicial.

Embora o estágio supervisionado ofereça meios para que o (a) acadêmico (a) tenha condições de entender a indissociabilidade entre a teoria e a prática, como parte fundamental do percurso formativo na graduação, alguns estudantes ainda relataram diretamente que não conseguiram compreender essa articulação, dificuldade que parece estar presente na formação na universidade, sendo reforçada no campo de estágio. Nossa interpretação é que prevalece a ideia dicotômica que relaciona o estágio ao momento de pôr em prática o que se aprende de maneira teórica na universidade. Superar essa representação ainda se mostra um desafio.

A pesquisa ainda mostrou o movimento de contradições presentes no estágio, os relatos dos estagiários mostraram que o estágio é orientado sempre como um processo indagativo, crítico das condições concretas da Educação do Campo, eles falam sobre isso, embora não percebam que os aspectos da formação são utilizados para questionar a realidade, posta na prática de ensino nas escolas campo. Outra contradição é expressa nos relatos sobre as realidades observadas nas escolas campo, como: ausência de um amplo e adequado espaço físico, merenda, salários e professores adequados, transporte escolar, ancorando esses problemas na legislação, na estrutura de classes, nas relações de poder, mas sem a clara compreensão de que esses aspectos foram estudados na formação inicial.

Entendemos que, embora o curso estudado assegure o conhecimento do referencial teórico - prático, conforme seu PPC (2013), se faz necessário focar no entendimento da especificidade da indissociabilidade entre teoria e prática e sua importância na composição da práxis. Esse objetivo carece de ser reforçado para que o(a) estagiário(a) supere uma representação de estágio, a partir de uma abordagem dicotômica.

No que se refere a concepção de Educação do Campo sustentada pelos estudantes do estágio, identificamos aspectos que podem ser associados a uma epistemologia crítica:

[...]. As orientações para o estágio e a própria formação do curso promovem a aproximação do aluno com a realidade do campo de trabalho, ajuda a entender o confronto com a diversidade de práticas necessárias nas escolas do campo, e o como manter as especificidades de uma educação campesina, como (...) possibilidades e superação dos desafios frente a realidade do campo (Estagiária Adália).

[...]. É papel do professor/a da educação do campo oferecer aos alunos/as novas estratégias pedagógicas e aprendizagem significativa (...), pois a escola campo exige atitude emancipadora, o que deve ser uma constante entre educandos e educadores, para fazer reconhecer seus papeis no processo ensino-aprendizagem e na transformação dos sujeitos envolvidos (Estagiária Rosa). 
[...]. O estágio nos possibilitou discutir brevemente sobre a educação não-escolar, mas aprofundou na função do educador social, aquele que atua na educação do campo. Sua postura é crítica e influi na práxis educacional, e como educadores sociais sempre devemos ampliar as atividades desenvolvidas nos vários espaços sociais ligados ao campo (Estagiária Hortência).

Os trechos mostram que embora os estudantes não se reportem diretamente aos aspectos citados como constituidores de uma concepção de educação do campo crítica e contra hegemônica, identificamos um discurso que expressa conhecimento sobre a função social do professor e da educação do campo, aspectos políticos, éticos, de maneira que, no conjunto, os(as) estagiários(as) reafirmam uma concepção ligada à transformação e a emancipação social.

Ainda foi possível identificar alguns aspectos podem ser associados a uma concepção de educação do campo contra hegemônica e transformadora,

[...]. O estágio nos ajuda na consolidação de uma educação do campo voltada a conscientização e a liberdade! Como mostram os movimentos sociais, nossa ação docente pode e deve ser ética, política, problematizadora do social, como delibera Paulo Freire (Estagiário Cravo).

Os resultados da pesquisa nos permitem recomendar que o estágio curricular supervisionado promove a conscientização do que seja uma educação crítica numa perspectiva de qualidade social, mas ainda se faz necessário avançar na construção de um discurso e ideário pedagógico literalmente articulado à concepção de educação libertadora.

\section{Considerações finais}

A pesquisa mostrou que o estágio possibilita aos/às estudantes, subsídios e elementos teórico-práticos relacionados à prática curricular que evidência a complexidade do trabalho docente no estágio, o que favorece trocas de experiências com os pares (alunos, professores da escola campo e da universidade), união das práticas profissionais às práticas sociais, inserção coletiva na instituição educativa, embora, ainda faz-se necessário, impulsionar o entendimento do que vem a ser a indissociabilidade entre teoria e prática, para que a prática docente seja práxis, no sentido de contribuir para superar a manutenção de uma concepção dicotômica de estágio.

A pesquisa ainda colocou em evidência, aspectos constitutivos de uma concepção de Educação do Campo, a partir de uma lógica inovadora, revolucionária e como tal, contra hegemônica entre os estagiários em seu processo formativo na universidade pública, o que reforça o fato que o estágio curricular supervisionado na Educação do Campo tem possibilidade de ação libertadora e insurgente e isso configura respeito à luta e militâncias dos movimentos sociais e dos Movimentos Sociais do Campo.

A concepção de Educação do Campo dos estagiários, tende a ser edificada em aspectos político, ético e social, pois eles problematizam a realidade escolar. Em nosso entendimento, o que se faz necessário, é investimento na construção de uma concepção teórica, epistemologicamente referenciada. O que pode 
resultar na expressão de uma educação consciente, voltada ao exercício da cidadania, a formação e sujeitos politizados entre os (as) estagiários(as), a instituição proponente, a concedente, bem como a comunidade.

Como desafio, o campo de atuação dos estudantes egressos, se apresenta como uma realidade a ser enfrentada tanto por parte do Sistema Educacional e suas respectivas instituições como um todo, quanto por parte da categoria de professores/as e também dos fóruns nacional e estaduais da Educação do Campo e próprios Movimentos Sociais. Essa é uma demanda posta devido ao Curso estar formando seus primeiros professores/as em Educação do Campo com habilitação em Artes Visuais e Música, sendo que os únicos do país ofertados pela Universidade Federal do Tocantins nos Câmpus de Arraias e Tocantinópolis, hoje pertencente a Universidade Federal do Norte Tocantinense (UFNT).

Esperamos que a pesquisa tenha relevância para a área de estudos da Educação do Campo, principalmente, no aspecto do Estágio Curricular Supervisionado, uma temática ainda pouco explorada como campo de pesquisa e que contribua para a revisão e o fortalecimento de formas de consolidação e na construção de uma concepção de Educação do Campo, com sólida formação teórica e epistemológica, que resulte na expressão de uma educação consciente, voltada ao exercício da cidadania, a formação de sujeitos críticos. Dessa forma, o estágio se fará presente para/na Educação do Campo como referência de qualidade, quer seja por ser mediadora de conhecimento, quer seja por suscitar a crítica e o desejo de intervenção, um movimento importante na composição de uma Educação do Campo como alternativa libertadora e emancipadora dos povos do campo, neste caso estudado, mediado pelos conceitos e metodologias no campo formativo das Arte Educação mediado pela linguagem e conhecimento das Artes Visuais e Música.

\section{REFERÊNCIAS}

AIRES, Berenice Feitosa da Costa; COSTA, Samara Queiroga et.al. (Orgs.). Manual de estágios. Palmas: Fundação Universidade Federal do Tocantins, 2016.

ANJOS, Eliane Rodrigues dos; BORGHI, Idalina Souza Mascarenhas; PORTO, Klayton Santana. Estágio supervisionado ciências da natureza na educação do campo: relato de experiência da escola municipal rui barbosa, comunidade do segredo-BA. Seminário Gepráxis, Vitória da Conquista -Bahia -Brasil, v. 6, n. 6, p 973-988, 2017.

BARRA, Valdeniza Maria Lopes da. Formação e atuação do pedagogo a partir da lei n. 9.394/96: questões velhas e novas. Revista e-Curriculum, São Paulo, v.18, n.2, p. 911-929 abr./jun. 2020.

BEZERRA, Maria Cristina dos Santos; LIMA, Elianeide Nascimento. A Prática de Estágio Supervisionado no Curso de Pedagogia da Terra da UFSCAR: Lições, Aprendizados e Desafios. In: BEZERRA NETO, Luís; BEZERRA Maria Cristina 
dos Santos e NETO José Leite. Na Luta pela Terra, a conquista do conhecimento. São Carlos: Pedro \& João Editores, 2013.177p.

BRASIL, MEC. Lei n 11.788/2008. Dispõe sobre o estágio de estudantes. Brasília-DF, 2008.

BRASIL, UFT. Projeto Pedagógico do Curso de Licenciatura em Educação do Campo. Arraias-TO, UFT, 2013.

BRASIL, CNE/CEB. Lei no 35/2003. Dispõe sobre as normas para a organização e realização de estágio de alunos do Ensino Médio e da Educação Profissional. Brasília: MEC/CNE/CEB, 2003.

BRASIL. Resolução n 2, de $1^{\circ}$ de julho de 2015. Define as Diretrizes Curriculares Nacionais para a formação inicial em nível superior. Brasília: MEC/CNE, 2015.

BRASIL. Resolução do Conselho de Ensino, Pesquisa e Extensão (CONSEPE) no 20/2012. Dispõe sobre as normas para os estágios curriculares não obrigatórios realizados por estudantes regularmente matriculados na Universidade Federal do Tocantins. Palmas: UFT, 2012

\section{BRASIL, UFT. Regulamento para Estágio Curricular Supervisionado do} Curso de Licenciatura em Educação do Campo: códigos e Linguagens com Habilitação em Artes Visuais e Música, Arraias-TO, 2016.

GOMES, Carlos Alberto Faísca Fernandes. Perspectivas para uma educação musical no âmbito curricular das artes na educação básica: um estudo exploratório tendo por base a realidade Tocantinense. RBEC, V.5, E6760, 10.20873/UFT. RBEC/6780, 2020.

LIMA, Telma Cristiane Sasso de; MIOTO, Regina Célia Tamaso. Procedimentos metodológicos na construção do conhecimento científico: a pesquisa bibliográfica. Rev. Katálysis. 2007, vol.10, pp.37-45.

MAGALHÃES, Solange Martins Oliveira Magalhães; MOURA, Sílvia Adriane Tavares de. Educação do Campo e Formação de Educadores na Perspectiva do Ensino Desenvolvimental: Por uma Educação Crítica e Emancipatória aos Povos do Campo. Obutchénie: revista de didática e psicologia pedagógica/ Universidade Federal de Uberlândia, Programa de Pós-Graduação em Educação e Grupo de Estudos e Pesquisas em Didática e Desenvolvimento Profissional Docente. -Vol.5, n. 2 (mai./ago. 2020 - Prelo).

MOLINA, Mônica Castagna: SÁ, Laís Mourão: Licenciatura em Educação do Campo. In: Dicionário de Educação do Campo. (Orgs.); CALDART, Roseli Salete et al. Rio de Janeiro São Paulo 2013, p. 469 e 470. 
PIMENTA, Selma Garrido; LIMA, Maria Socorro Lucena Lima. Estágio e Docência. 2a. Ed. São Paulo: Cortez, 2004.

SAVIANI, Demerval. Pedagogia Histórico-Crítica: primeiras aproximações. 7a. Ed. Campinas, SP: Autores Associados, 2000.

ORIENTAÇÕES CURRICULARES PARA A EDUCAÇÃO INFANTIL DO CAMPO. Anais do I Seminário Nacional: currículo em movimento - Perspectivas Atuais. Belo Horizonte, novembro de 2010.

SILVA, Claudionor Renato da. Estágio: epistemologias e conversas de sala de aula/orientação. Editora Espaço Acadêmico- Goiânia-Goiás, 2020, 220 p.

Recebido em: 17 de setembro de 2020. Aceito em: 23 de abril de 2021. Publicado em: 15 de dezembro de 2021. 